\title{
Synergies of Electric Urban Transport Systems and Distributed Energy Resources in Smart Cities
}

\author{
Christian F. Calvillo, Student Member, IEEE, Álvaro Sánchez-Miralles, and José Villar
}

\begin{abstract}
Transport systems and buildings are among the bigger energy users inside cities. Abundant research has been developed about these systems (facilities and transport). However, synergies among them are commonly overlooked, not taking advantage of the possible benefits of their joint coordination and management. This paper presents a linear programming model to find the optimal operation and planning of distributed energy resources (DER) in a residential district, while considering electric private and public transport systems, in particular electric vehicles and metro. Hence, the main contribution of this paper is the analysis of synergies of such an interconnected scheme. It has been assumed that part of the metro regenerative braking energy can be stored into electric vehicles' (EVs') batteries, so that it can be used later for other trains or for the EV itself. Several case studies have been proposed using data from a residential district and a metro line in Madrid. The obtained results show important cost savings in the overall system, especially a significant power cost reduction for the metro system.
\end{abstract}

Index Terms-Demand response, distributed energy resources, electric vehicle, energy management, public transport systems, smart city.

\section{NOMENCLATURE}

Sets
$h$

$h V$

Hour (1-24)

(

Off-peak hours for the electric time-of-use

$h M s, h M w$ tariffs

$h P s, h P w$

Summer and winter mid-peak hours for time-of-use tariffs

$m S, m W, m$

Summer and winter peak hours for the time-of-use tariffs

$m$, $m W, m$ Summer (3-8), winter (1,2,9-12) and all months $(1-12)$

$y \quad$ Years $(1-$ pLifespan $)$

${ }_{24} \quad c, v$

Type of houses $(1-4)$ and EV $(1,2)$

\section{Parameters}

pLifespan

Expected lifespan for $\mathrm{PV}$ and $\mathrm{HP}$ systems in the study (20 years)

pHouseNum, Number of equivalent clients per house pEVnum and EV user types

Manuscript received September 29, 2016; revised May 17, 2017; accepted September 2, 2017. The work of C. F. Calvillo was supported by the Erasmus Mundus Ph.D. Fellowship. The Associate Editor for this paper was E. Kosmatopoulos. (Corresponding author: Christian F. Calvillo.)

The authors are with the Institute for Research in Technology, ICAI School of Engineering, Comillas Pontifical University, Madrid, Spain (e-mail: christian.calvillo@iit.comillas.edu; alvaro@comillas.edu; jose.villar@iit.comillas.edu).

Color versions of one or more of the figures in this paper are available online at http://ieeexplore.iee.org.

Digital Object Identifier 10.1109/TITS.2017.2750401

pEVcap
pCost $T_{y}$,
pCost $E_{y}$,
pSellE
pSellEpriceH
pBuyEprice $H_{m, h}$,
pBuyEprice $M_{m, h}$
pFixEpow,
pFixTpow

Max. storage capacity per EV (kWh)

Annual increment of thermal and electric energy base buying and selling prices (\%)

Electricity base selling price $(€ / \mathrm{kWh})$

Electricity base residential and commercial prices (€/kWh)

Annual access tariff for residential Electric and thermal power (€/kW, €/client)

pCostPV, pCostHP pCostBat pOMfixPV, pOMfixHP

pDemandTh pDRequipCost

pDays $M_{m}$ pEffBat $p A v E V_{v, h}$ pSOCinitE $V_{v, h}$ pSOCminE $V_{v, h}$ pPeakPowMet, pMidPpowMet, pOffPpowMet pMetLoad $h$, pMetReg ${ }_{h}$

Positive Variables

vPowPV $V_{c}$ ${ } \operatorname{ProdPV}_{c, m, h}$ ${ } \mathrm{BatCap}_{c}$ $v S O C_{c, m, h}$ ${ } \mathrm{ChBat}_{c, m, h}$ $v_{\text {DisBat }}, m, h$ ${ }$ PowHP $_{c}$ ${ } \operatorname{ProdHP}_{c, m, h}$ $v_{\text {HPenInput }}, m, h$ $v_{\text {GridEnBuy }}, h$ ${ }_{\nu}$ GridEnSell $_{m, h}$ vThBuy ${ }_{c, m}$

$v$ DemandNew $_{c, m, h}$
Total cost per installed Watt of PV and $\mathrm{HP}$ (€/MW)

Total upfront cost of batteries (€/MWh)

Fixed annual operation and maintenance costs per Watt of PV and HP (€/MW)

Total thermal demand (MWh) Costs of equipment required to do load shifting (€/client) Number of days in month $m$ Battery charge/discharge eff. (\%) Max. available capacity of EVs (kWh) SOC of the arriving EV (\%) Min. SOC requirement for EV (\%) Annual access tariff for commercial (metro) electric power at peak, mid-peak and off-peak hours (€/kW) Base electric demand curve and regenerative braking energy for the metro trains (MWh)

PV installed capacity (MW) Electric PV production (MWh) Battery installed capacity(MWh) Battery State-of-Charge (MWh) Battery charged/discharged Energy (MWh)

HP installed capacity (MW)

Thermal HP production (MWh)

Electricity for HP production (MWh)

Total energy transaction to the grid (buying and selling) (MWh) Thermal energy bought (natural gas) from the utility (MWh)

New consumption curve after changing the base profile (MWh) 


$\begin{array}{ll}v \text { PowElect }_{c} & \text { Contracted annual electric power (MW) } \\ v \operatorname{SOCEV}_{v, m, h} & \text { EV State-of-Charge (MWh) } \\ v \text { ChEV }_{v, m, h} & \text { Energy charged/discharged to/from } \\ v \text { DisEV }_{v, m, h} & \text { EV (MWh) } \\ v \text { LoadMetNew }_{m, h} & \begin{array}{l}\text { New metro consumption curve after } \\ \text { changing the base profile (MWh) }\end{array} \\ v \text { PowPeakMet }, & \text { Contracted annual electric power for } \\ v \text { PowMidpMet, } & \text { the metro system at peak, mid-peak } \\ v \text { PowOffpMet } & \text { and off-peak hours (MW) } \\ v \text { ChMetro }_{v, m, h} & \text { Energy charged /discharged from EV } \\ v \text { DisMetro }_{v, m, h} & \text { to the metro system (MWh) }\end{array}$

$31 \quad$ Free Variables

\begin{tabular}{|c|c|}
\hline$v$ GridEnTr$_{m, h}$ & Grid energy transaction (MWh) \\
\hline $\begin{array}{l}\text { costDist }_{E E} \\
\text { costDist }_{\text {Pow E }}\end{array}$ & $\begin{array}{l}\text { Electric energy and power cost for the } \\
\text { considered district }(€)\end{array}$ \\
\hline $\operatorname{cost}_{E T}$ & Thermal energy and power cost \\
\hline cost $_{\text {Pow }}$ & for the considered district $(€)$ \\
\hline $\operatorname{cost}_{P V}$ & PV investment costs $(€)$ \\
\hline$O M_{P V}$ & PV operation and maintenance costs $(€)$ \\
\hline $\operatorname{cost}_{\text {Bat }}$ & Battery investment costs $(€)$ \\
\hline $\operatorname{cost}_{H P}$ & Heat pump investment costs $(€)$ \\
\hline$O M_{H P}$ & HP operation and maintenance costs (€) \\
\hline $\operatorname{cost}_{D R}$ & Costs for DR equipment (€) \\
\hline $\operatorname{costMet}_{E E}$ & Electric energy and power cost for th \\
\hline $\begin{array}{l}\operatorname{costMet}_{\text {Pow }} \\
\text { cost }_{E V}\end{array}$ & EV costs due to extra battery \\
\hline$C O S t_{E V}$ & degradation $(€)$ \\
\hline
\end{tabular}

\section{INTRODUCTION}

$\mathbf{I}$ NSIDE cities, the quality of life of inhabitants is directly related to the quality of transport systems available. However, transport is a large energy consumer and one of the main air polluters within the city, which can translate to important health costs [1]. Therefore, future transport systems should be cleaner and more efficient.

In this general context of emission reduction and energetic efficiency, several technologies and strategies for improving urban rail systems efficiency have been proposed in the literature. A review of such solutions has been presented in [2], where 5 main groups of action have been identified: regenerative braking, efficient driving, comfort functions, traction efficiency, and smart measurement and management.

Regenerative braking consists of recovering the braking energy of a vehicle in the form of electricity to be reused in the same or other vehicle or system. Given the nature of the metro, with numerous and frequent stops, regenerative braking can potentially provide important energy savings [3]. Three main strategies can be implemented to maximize the use of braking energy. For instance, an energy-wise optimal timetable has been presented in [4], where a programming problem is designed to synchronize the braking of metro trains arriving at a station with the departing of other trains in the same or other stations within the same electrical section. By doing this, the regenerated energy is directly used for the starting acceleration of other trains without the need of storage. The second alternative consists of the use of energy storage systems to save the braking energy. González-Gil et al. [3] analyze the main storage technologies for both on-board and wayside applications. The main benefit of this solution is that there is no need for a synchronized departing train, but the extra infrastructure for storage represents higher costs. Lastly, reversible substations can be implemented to return the braking energy back to the grid, as shown in [5].

From the point of view of polluting emissions, many cities are restricting fuel oil vehicles transit through their urban centers (for instance, Madrid enters in an alert state where transit is heavily restricted if the $\mathrm{NO}_{2}$ concentration goes over $400 \mathrm{ug} / \mathrm{m}^{3}$ for three or more consecutive hours [6]), incentivizing its replacement with electric vehicles (EV). There are many studies in EV technologies concerning charge and discharge control (see [7] where a review of different smart charging strategies has been presented), use of their storage capability [8], their impact on the grid [9], and how smart charging facilitates the integration of renewable energies, [10].

While EV interaction with the grid has been widely studied, electric public transport systems have not been so much analyzed in such a way. Furthermore, transport systems (besides EVs) interconnected to energy districts have been scarcely addressed in the literature, and despite that the connection between metro systems and EVs is unusual and has been barely studied, pilot projects like [11, p. 2] and the research project [12] have proven it possible, motivating further research on this scheme. Therefore, one of the main contributions of this paper is the quantitative analysis of interactions between DER (distributed energy resources) systems and electric public transport, a scheme not previously addressed in the literature. This analysis provides insight into possible economic benefits due to potential synergies of these systems, suggesting new possibilities of coordinated management on smart city environments.

The main objective of this paper is to analyze the synergies and assess the benefits of the interaction of electric public transport, private electric vehicles and distributed energy resources, by modeling the energy consumption and regenerative braking generation of metro trains connected to an electrical substation, and a set of electric vehicles in a residential district with different energy loads and distributed energy resources in the form of PV panels, air-source heat pumps, static battery storage and demand response schemes.

A linear programming (LP) problem has been proposed, due to its relatively simple modelling and fast solution times, to compute the optimal DER capacity to be installed and its operation as a function of the loads, EV and metro scenarios analyzed, and to assess the benefits in energy and power costs for both the metro electrical substation and the district considered. The DER considered in this study, are photovoltaic (PV) panels, air-source heat-pump (HP), stationary batteries (apart from EVs' batteries) and demand response systems. Note that there are more detailed non-linear DER systems models, commonly used for real-time operation problems. However, for long-term planning models (like the one proposed in this paper) where such fine detail is no required, the linear version is commonly preferred [13]. 
For the input parameters, average train energy consumption values with distance and trip time data from line 3 of Metro de Madrid have been used to compute the consumption and generation profiles of metro trains. Solar irradiation values corresponding to Madrid have been used for the PV production, and real Spanish energy tariffs have been considered. Typical residential load profiles have been used and a real Madrilenian district has been considered for the study.

To assess the benefits of the interconnections and joint operation of EV, metro and DER systems, four case studies have been analyzed: a base case with independent metro and EV operation, and district loads without DER; a second case optimizing EVs and metro together but still no DER; a third case implementing DER systems but optimizing metro and EVs separately by removing their electrical connection; and the complete case that optimizes metro and EVs together and computes the optimal DER systems investments.

The rest of the paper is organized as follows. In Section 2, a brief description of the optimization model can be found. In Section 3 the full mathematical formulation is presented. In Section 4 the input parameters for the model and the case studies are described. Results of the case studies, discussion of their implications and a comparison between cases are provided in Section 5. Concluding remarks can be found in Section 6.

\section{MOdel Description}

The proposed model considers a metro line section and its electrical substation, an EV parking and a residential energy district corresponding to a neighborhood of the city with household loads and DER systems. The electric substation of the metro electrical section is connected to the grid that supplies energy to the trains and to other metro related systems. The substation is also connected to the parking where EVs can be parked and used as storage for regenerated braking energy. The parking is also connected to the grid and to the energy district.

As in [14], the metro-EV connection system is basically composed by the railway power line, an electrochemical energy storage system composed by ultra-capacitors and the charging posts for the electric vehicles. The line side has a transformer and an inverter connected to the DC link for bidirectional power flows. The core of the system is a DC link with the AC network with the capacitors and all the power electronic converters connected together. The main function of the DC link is to permit the power flow, controlling the voltage level at the coupling point. The charger points are bidirectional for vehicle-to-grid (V2G) functionalities. A simplified scheme of the system is shown in Fig. 1 (taken from [14], note that the DC connections are in black and AC connections are in red).

The block diagram of the complete model is shown in Fig. 2 . Black lines represent electric energy connections and the arrows illustrate the energy flow directions. Blue squares represent loads and/or generators, the three interconnected systems are the brown squares, and the electric grid has been represented as a red square. This general model can be particularized for the four case studies mentioned, by combining the

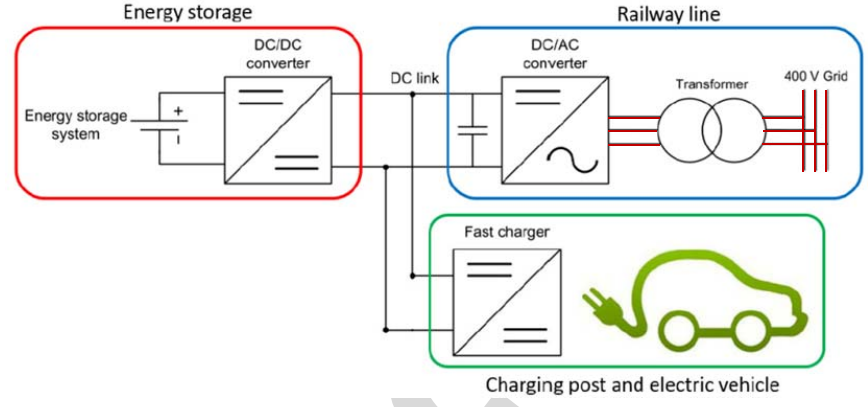

Fig. 1. Block diagram of the EV-metro connection.

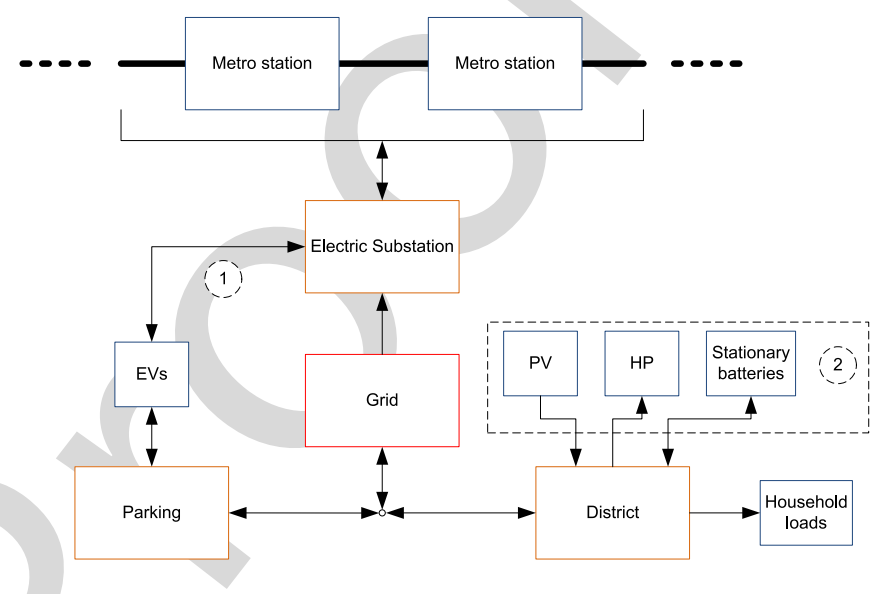

Fig. 2. Block diagram of the proposed system.

possibility of not implementing DER systems (removing (2) in Fig. 2) or separately optimizing EVs and metro operation (removing connection (1) in Fig. 2). It is important to remark that it is considered that all the DER and EV costs are assigned to the district and not to the metro system.

\section{Mathematical Formulation}

This section describes the linear optimization model proposed. The model has been implemented with the GAMS mathematical modelling tool, and uses CPLEX as the LP solver. A standard desktop PC with an Intel i7 processor has been used to run the model (running time of less than a $1 \mathrm{~min})$. For the sake of brevity, the constraints governing the DER systems (PV, HP, batteries, and demand response systems) have not been included here, but can be found in [15].

District's demand response has been modeled as the ability to shift residential loads throughout the day, considering that only certain appliances and loads (such as the washing machine or the dishwasher) can be shifted. According to [16], the washing machine, dryer and dish washer represent the $13.3 \%$ of the total electric consumption of a typical Spanish household; hence, the total demand response (load shifting) has been established to a maximum $13 \%$ of total daily load (respecting a minimum load of $100 \mathrm{~W}$ per house at all times). Also, it is considered that the buildings in the district do not have any preexisting DER installation. The model considers a typical year's operation characterized by 12 months, each one has been represented by a typical 
day ( 12 days $\times 24 \mathrm{~h}=288 \mathrm{~h}$ model the year), and has been replicated for the total length of the study (20 years) [15]. For the sake of brevity, only the complete system has been described, as the other models differ only slightly.

\section{A. Objective Function}

The proposed objective function minimizes the costs of all the considered systems including the metro, the EVs and the prosumers (producer-consumers) of the district modeled in an aggregated manner. These costs correspond to the net energy costs and the costs of investing and maintaining the DER systems:

$$
\begin{aligned}
& \min \left\{\operatorname{cost} \text { Dist }_{P o w E}+\operatorname{cost}_{\text {Dist }} E E+\operatorname{cost}_{P V}+O M_{P V}\right. \\
& +\operatorname{cost}_{\text {Bat }}+\operatorname{cost}_{E T}+\operatorname{cost}_{P o w T}+\operatorname{cost}_{H P}+O M_{H P} \\
& \left.+\operatorname{cost}_{D R}+\operatorname{cost}_{\mathrm{Met}} \mathrm{t}_{E E}+\operatorname{cost}_{\mathrm{Met}} \mathrm{towE}_{\mathrm{E}}+\operatorname{cost}_{E V}\right\}
\end{aligned}
$$

Terms in (1) have been detailed in equations (2) - (14). It can be seen that (2) is the cost of the contracted electricity power, (3) sums up the electricity costs and incomes due to the transactions of the district with the grid, and (4) and (5) correspond to the thermal energy and power costs respectively. Equations (6) to (11) describe the distributed resources equipment costs including maintenance. The cost of the district stationary batteries considers a replacement every 8 years [17]. Metro energy and power costs have been computed with (12) and (13), respectively.

Lastly, considering that the EV battery might suffer extra degradation from additional charge/discharge cycles produced by the metro usage [8], equation (14) has been used to add in the objective function the extra cost for the EV users, as the cost of a new set of batteries, paid at the beginning of the study. In other words, it has been considered that EV battery packs should be replaced every 5 to 8 years [17], [18] (3 to 4 replacements of the EV batteries during the 20 years of the study length), but due to the extra charging/discharging, it has been considered that the battery pack would need an extra replacement in that time.

This objective function has been formulated considering a total lifespan of 20 years, with investments, if any, taking place at the beginning of the study period.

$$
\begin{aligned}
& \text { cost Dist Pow E } \\
& =\sum_{y}\left(p \text { Cost } E_{y} * \text { pFixEpow } * \text { P PowElect }\right) \\
& \text { cost } \text { Dist }_{E E} \\
& =\sum_{y, m, h}\left(p \operatorname{Cost} E_{y} * \text { pDays } M_{m}\right. \\
& \text { * (pBuyEprice } H_{m, h} * v \text { GridEnBuy }_{m, h} \\
& \left.\left.- \text { pSellEprice } H_{m, h} * v \text { GridEnSell }_{m, h}\right)\right) \\
& \operatorname{cost}_{E T}=\sum_{y, c, m}\left(p \operatorname{Cost} T_{y} * p \text { Days } M_{m} * v T h B u y_{c, m}\right) \\
& \operatorname{cost}_{\text {PowT }}=\text { pLifespan } * 4 * \text { pHouseNum } * \text { pFixTpow }
\end{aligned}
$$

$$
\operatorname{cost}_{P V}=\sum_{c}\left(p \operatorname{Cost} P V * v \operatorname{Pow} P V_{c}\right)
$$

$$
\begin{aligned}
& O M_{P V}=\sum_{C}\left(p O M f i x P V * v P o w P V_{c} * \text { pLifespan }\right) \\
& \operatorname{cost}_{B a t}=\sum_{c}(\text { pCost Bat } * v \text { BatCapc }) \\
& \text { cost }_{H P}=\sum_{c}\left(p \operatorname{Cost} H P * v \text { Pow } H P_{c}\right) \\
& O M_{H P}=\sum_{C}\left(p O M f i x H P * v P o w H P_{c} * \text { pLifespan }\right) \\
& \operatorname{cost}_{D R}=4 * \text { pHouseNum } * \text { pDRequipCost } \\
& \text { cost Met }_{E E} \\
& =\sum_{y, m, h}\left(p \operatorname{Cost} E_{y} * p \text { Days } M_{m}\right. \\
& \left.* \text { pBuyEprice } M_{m, h} * \text { LLoadMet New } m, h\right) \\
& \text { cost Met } t_{\text {Pow }} \\
& =\sum_{y}\left(p \operatorname{Cost} E_{y} *(\text { pPeakPowMet }\right. \\
& \text { *vPowPeakMet + pMidPpowMet } \\
& \text { *v PowMidpMet }+ \text { pOff PpowMet } \\
& \text { *vPow OffpMet)) } \\
& \operatorname{cost}_{E V}=p \operatorname{Cost} B a t * p E V \text { num } * p E V \text { cap }
\end{aligned}
$$

\section{B. Balance Equation}

Equation (15) is required to balance the total energy consumption and production, where all the energy that enters each node is positive and the energy that leaves the node is negative, and (16) has been used to separate the positive and negative parts of the energy transactions with the grid to use the appropriate pricing for selling and buying electric energy. Similarly, thermal energy is balanced with (17). The energy that is not supplied with the HP is bought from the natural gas mains.

$$
\begin{aligned}
& \text { vGridEnTr } r_{m, h} \\
& =\sum_{c}\left(v \text { DemandNew }_{c, m, h}-v \operatorname{ProdP} V_{c, m, h}\right. \\
& \text { - vDisBat }{ }_{c, m, h} * p E f f B a t \\
& \left.+v_{\text {ChBat }}{ }_{c, m, h} / p \text { Eff Bat }+v \text { H PenInput } t_{c, m, h}\right) \\
& +\sum_{v}\left(-v D i s E V_{v, m, h} * p E f f B a t\right. \\
& \left.{ }_{+}{ } \operatorname{ChE} V_{v, m, h} / p E f f B a t\right) \\
& { }_{v} \text { GridEnTr } r_{m, h} \\
& =v \text { GridEnBuy }_{m, h}-v \text { GridEnSell }_{m, h} \\
& \text { vThBuy } \\
& =\sum_{c}\left(p \text { Demand } h_{c, m}-\sum_{h}\left(\operatorname{vProdH} P_{c, m, h}\right)\right)
\end{aligned}
$$

\section{EVs State-of-Charge Constraints}

EVs have a set of constraints that govern its behavior: equations (21) and (22) model EV stored energy that changes

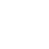


over time and type of user, as well as the minimum SOC requirement for the EV before being driven. Moreover, it can be seen in (24) that the EVs can arrive at the parking lot with a preexisting stored energy that could go to the metro trains.

$v S O C E V_{v, m=1, h=0}=0$

$v S O C E V_{v, m, h=0}=v S O C E V_{v, m-1, h=24} \forall m \in[2,12]$

$$
\begin{aligned}
v S O C E V_{v, m, h=1}= & v S O C E V_{v, m, h=24} \forall m \in[2,11] \\
v S O C E V_{v, m, h} \leq & p A v E V_{v, h} * p E V \text { num } \\
\text { vSOCE } V_{v, m, h} \geq & p S O C m i n E V_{v, h} * p E V n u m \\
\text { vDisE } V_{c, m, h} \leq & v S O C E V_{c, m, h-1} \\
\text { vSOCE } V_{v, m, h}= & \text { vSOCE } V_{v, m, h-1}-v \text { DisE } V_{v, m, h} \\
& +v C h E V_{v, m, h}+p S O C i n i t E V_{v, h} \\
& * \text { pEVnum }- \text { visMetro } o_{v, m, h} \\
& +v \text { ChMetro }{ }_{v, m, h}
\end{aligned}
$$

\section{Metro Constraints}

Lastly, metro constraints have been included to limit the energy used to charge EVs from the available regenerative braking energy (25) and to compute the new electric net load curve of the trains, modified from the original by the EV discharged energy (26). Equations (27) - (31) have been used to calculate the contracted power at different time-of-use tariff periods.

$$
\begin{aligned}
& \sum_{v} v \text { ChMetro }_{v, m, h} \leq \text { pMet Reg }{ }_{h}
\end{aligned}
$$

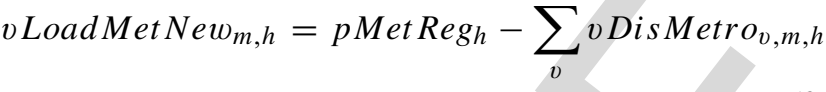

$$
\begin{aligned}
& v \text { Pow OffpMet } \geq \text { vLoadMetNew }, \text { hO } \\
& v \text { PowMidpMet } \geq \text { vLoadMet New } m \text { S, hMs } \\
& v \text { PowMidpMet } \geq \text { vLoadMet New } w_{m, h M w} \\
& v \text { PowPeakMet } \geq \text { vLoadMetNew } m \text { S, hPs } \\
& v \text { PowPeakMet } \geq \text { vLoadMet New } w, h P w
\end{aligned}
$$

\section{CAse Study Description AND PARAMETERS}

\section{A. Substation Energy Profiles}

Line 3 of Madrid's metro, selected for this study, has 6 electrical substations serving the 18 metro stations [4], [19]. The exact location of the substations is not publicly available. However, it seems sensible to consider that there is one substation every three metro stations. Therefore, it has been considered that there is one substation at the beginning of the line, distributing energy to the stations of Villaverde Alto, San Cristóbal, Villaverde Bajo-Cruce, and partly to the Ciudad de los Ángeles station, where the second substation should be located approximatively (see Fig. 3, taken from [20]).

The train traction energy has been calculated with the average energy consumption per distance and per trip time values from [21], and with the metro line 3 interstation distances and trip times taken from [22] and [23] respectively.

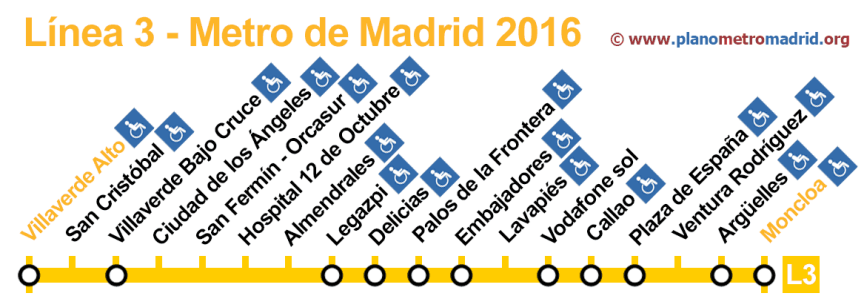

Fig. 3. Station plan of Madrid's metro line 3 .

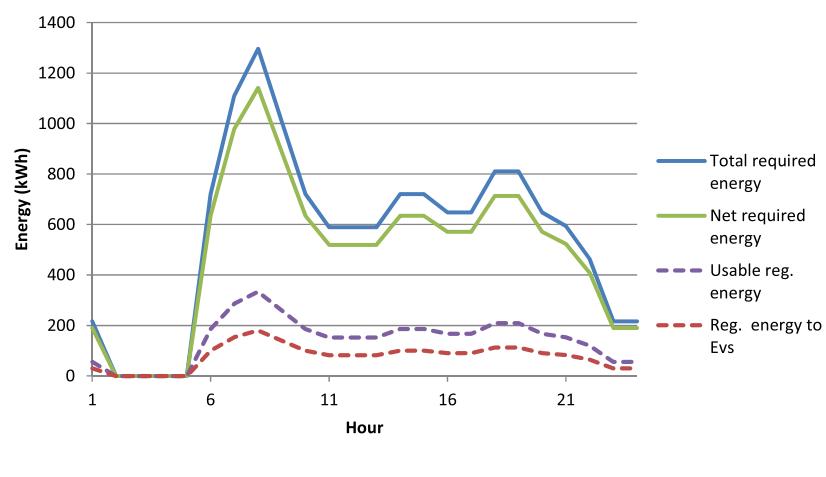

Fig. 4. Villaverde Alto substation energy profiles.

It is important to remark that, according to [3], it has been considered that the total train energy usage includes traction loads ( $80 \%$ of total consumption to move the train) and nontraction loads ( $20 \%$ of the total consumption corresponding to station loads, ventilation, etc.); and that only $1 / 3$ of the train traction energy can be reused. From this recovered energy, $43 \%$ has been supposed to supply other trains, $50 \%$ to supply external EV systems, and 7\% is lost [24].

Train catenary lines are normally connected to two electrical substations so the energy feed to the train comes from both. Due to the lack of information, it has been considered that the same energy is required by the train in both directions, and that the energy consumption is equally shared between the two substations. Hence, the energy usage from the trains, moving in the section of the metro line selected (including the non-traction energy) is $54 \mathrm{kWh}$, and the regenerative braking energy recovered is $15 \mathrm{kWh}$.

Madrid's metro system runs in time intervals (i.e. a train passes through the stations every certain number of minutes) where the duration changes depending on the hour of the day and the day of the week. Taking the average time intervals of metro line 3 for the standard week day (Monday to Thursday) [23], and considering the energy usage previously mentioned, the full energy profile for the electrical substation has been calculated.

\section{B. EV Availability}

The San Aureliano parking lot with 194 spots [25] has been selected as the parking for the EVs, due to its proximity to the considered metro stations previously described.

In a Madrilenian residential neighborhood, the normal practice in a week day is that residents leave for work in the 


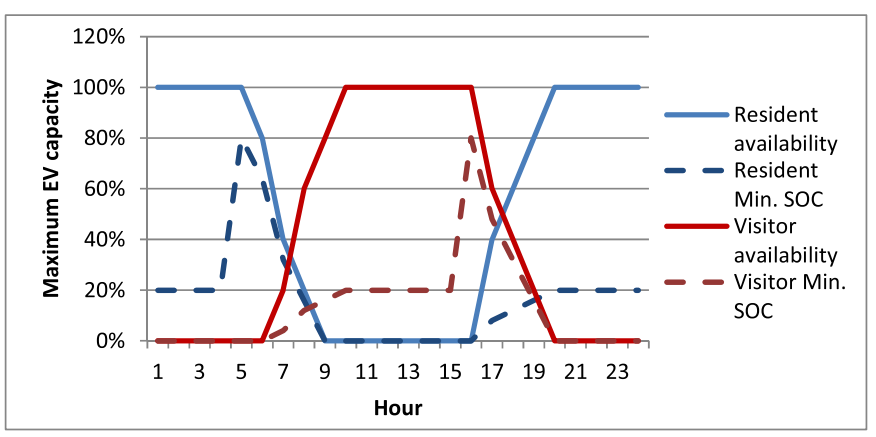

Fig. 5. EV user availability and minimum State-of-charge requirement.

morning, around $6 \mathrm{~h} 00-8 \mathrm{~h} 00$, and come back home around $17 \mathrm{~h} 00-19 \mathrm{~h} 00$. It is also common practice that people living in suburbs, arrive in their cars to parking lots conveniently close to metro or commuter train stations, using the empty places of the residents and continuing their journey in public transport systems. Therefore, two kinds of EV users with different usage profiles have been modelled: EV1 and EV2. EV1 correspond to the usage profile of the $194 \mathrm{EVs}$ belonging to the residents, while EV2 correspond to the usage profile of the $194 \mathrm{EVs}$ belonging to the visitors, which occupy the free places of the parking when left free by the residents that go to work. Basically EV1 corresponds to a night parking usage, while EV2 corresponds to a day parking usage. Fig. 5 illustrates the behavior of both EV users.

It has been considered that a minimum SOC of $20 \%$ is desired at all times the car is parked, but for the time the car leaves the parking lot, a minimum SOC of $80 \%$ is needed to comply with the requirement of EV users and the recommendations given by most manufacturers to extend battery life [26]. It has also been considered that the EV arrives to the parking lot with $40 \%$ of charge remaining (i.e. the energy required for the journey is $40 \%$ of total capacity).

\section{DER Characteristics}

Solar production has been calculated with hourly irradiance data from [27], corresponding to the solar characteristics of Madrid. The costs and performance parameters of the considered DER have been taken from [15].

Parameter pDRequipCost has been set to $250 €$ /house and represent the cost of the control devices needed for demand response [28].

\section{District Energy Profiles}

Household energy profiles are required to adequately plan and operate the DER systems and its integration with the metro substation. According to [29], residential clients in Spain can be classified in four types depending on the age of the head of the family and/or the presence of young children in the household, with different total annual energy consumption per type. This differentiation of energy consumption per client type has been used in this paper [30].

For thermal energy, it has been assumed that the users follow the same changes in percentage of total consumption
TABLE I

RESIDENTIAL ENERGY TARIFFS

\begin{tabular}{cccc}
\hline \hline & Peak & Mid-peak & Off-peak \\
\hline Electric energy (€/MWh) & 163.2 & 84.3 & 56.4 \\
Electric Power $(€ / \mathrm{MW})$ & & 49286.2 & \\
Time schedule & $13-23 \mathrm{~h}$ & $7-13,23-1 \mathrm{~h}$ & $1-7 \mathrm{~h}$ \\
\hline Natural gas variable $(€ / \mathrm{MWh})$ & 56.8 & \\
Natural gas fixed $(€ /$ year $)$ & 52.32 & \\
\hline \hline
\end{tabular}

TABLE II

MEtro ENERgy TARIFFS

\begin{tabular}{cccc}
\hline \hline & Peak & Mid-peak & Off-peak \\
\hline Energy $(€ / \mathrm{MWh})$ & 126.6 & 109.2 & 80.4 \\
Power $(€ / \mathrm{MW})$ & 59475.3 & 36676.8 & 8410.4 \\
Winter schedule & $17-23 \mathrm{~h}$ & $8-17 \mathrm{~h} \& 23 \mathrm{~h}$ & $0-8 \mathrm{~h}$ \\
Summer schedule & $10-16 \mathrm{~h}$ & $8-10 \mathrm{~h} \& 16-0 \mathrm{~h}$ & $0-8 \mathrm{~h}$ \\
\hline \hline
\end{tabular}

as in electricity. Moreover, it has been considered that most residential customers have a hot water tank or other means of thermal storage, so there is no an hourly demand curve. It has also been assumed that both the thermal and electric use follows the same monthly percentage pattern described in [29].

\section{E. Energy Price Parameters}

A time-of-use tariff has been assumed for the residential customer electricity consumption, including EV charging, which could be offered by an aggregator or retailer. The thermal energy, on the contrary, has been priced with a static tariff (often offered by the same retailers). With data taken from [31] and [32], Table I presents the electric power and energy tariffs selected. It is important to remark that it has been assumed that the prosumer can sell electricity back to the grid at a fixed price of $0.0421 € / \mathrm{kWh}$ (half of the midpeak buying price, corresponding to energy costs without network costs, only paid when consuming). Although detailed information about the energy transactions of Metro de Madrid is unavailable, it seems sensible to consider that the metro has a commercial high voltage tariff, like the one presented in [33], with time-of-use discrimination for both energy and power, and different time schedules for winter and summer months. Table II summarizes the selected metro tariff values selected for this study.

\section{F. Case Studies Description}

The case studies proposed in this paper have the objective of assessing the synergies between EVs and the metro trains, with and without DER investments. For the sake of clarity, they have been labeled with the abbreviation CS for Case Study, and two sub-indexes: $\mathbf{c}$ and d. Sub-index c refers to the connection metro-EV (see 1 in Fig. 2), and $\mathbf{d}$ to the DER systems in the district (see 2 in Fig. 2). Upper case subindexes indicate the existence of such element and lower case the absence of it.

Four case studies implementing three different versions of the model with a district size (residential load) equivalent to 
TABLE III

Energy Costs of All Case Studies

\begin{tabular}{|c|c|c|c|c|c|c|c|c|c|c|c|c|c|c|c|c|}
\hline \multirow{2}{*}{$\begin{array}{l}\text { Number } \\
\text { of EVs }\end{array}$} & \multicolumn{4}{|c|}{ Energy metro (M€) } & \multicolumn{4}{|c|}{ Electric energy district $(\mathrm{M} €)$} & \multicolumn{4}{|c|}{ Thermal energy district $(\mathrm{M} €)$} & \multicolumn{4}{|c|}{ DER invest. and maint. (M€) } \\
\hline & $\mathrm{CS}_{\mathrm{cd}}$ & $\mathrm{CS}_{\mathrm{Cd}}$ & $\mathrm{CS}_{\mathrm{cD}}$ & $\mathrm{CS}_{\mathrm{CD}}$ & $\mathrm{CS}_{\mathrm{cd}}$ & $\mathrm{CS}_{\mathrm{Cd}}$ & $\mathrm{CS}_{\mathrm{CD}}$ & $\mathrm{CS}_{\mathrm{CD}}$ & $\mathrm{CS}_{\mathrm{cd}}$ & $\mathrm{CS}_{\mathrm{Cd}}$ & $\mathrm{CS}_{\mathrm{cD}}$ & $\mathrm{CS}_{\mathrm{CD}}$ & $\mathrm{CS}_{\mathrm{cd}}$ & $\mathrm{CS}_{\mathrm{Cd}}$ & $\mathrm{CS}_{\mathrm{cD}}$ & $\mathrm{CS}_{\mathrm{CD}}$ \\
\hline 25 & 12.42 & 7.48 & 12.42 & 2.71 & 12.66 & 14.91 & 5.40 & 7.45 & 9.66 & 9.66 & 0.69 & 0.60 & 0 & 0 & 9.77 & 13.36 \\
\hline 50 & 12.42 & 7.86 & 12.42 & 2.83 & 12.85 & 14.76 & 5.74 & 7.27 & 9.66 & 9.66 & 0.65 & 0.60 & 0 & 0 & 9.52 & 13.40 \\
\hline 100 & 12.42 & 6.89 & 12.42 & 2.61 & 13.15 & 16.14 & 5.99 & 7.80 & 9.66 & 9.66 & 0.64 & 0.58 & 0 & 0 & 9.52 & 13.37 \\
\hline 150 & 12.42 & 6.28 & 12.42 & 2.11 & 13.49 & 16.99 & 6.01 & 8.14 & 9.66 & 9.66 & 0.59 & 0.48 & 0 & 0 & 9.87 & 13.99 \\
\hline 194 & 12.42 & 6.03 & 12.42 & 1.53 & 13.80 & 17.49 & 6.36 & 8.61 & 9.66 & 9.66 & 0.60 & 0.47 & 0 & 0 & 9.87 & 14.50 \\
\hline
\end{tabular}

TABLE IV

Power and Total Costs of All Case Studies

\begin{tabular}{|c|c|c|c|c|c|c|c|c|c|c|c|c|c|}
\hline \multirow{2}{*}{$\begin{array}{l}\text { Number } \\
\text { of EVs }\end{array}$} & \multicolumn{4}{|c|}{ Electric power metro (M€) } & \multicolumn{4}{|c|}{ Electric power district (M€) } & \multirow{2}{*}{$\begin{array}{l}\text { Other costs }(\mathrm{M} €) \\
\text { All case studies }\end{array}$} & \multicolumn{4}{|c|}{ Total costs $(\mathrm{M} €)$} \\
\hline & $\mathrm{CS}_{\mathrm{cd}}$ & $\mathrm{CS}_{\mathrm{Cd}}$ & $\mathrm{CS}_{\mathrm{CD}}$ & $\mathrm{CS}_{\mathrm{CD}}$ & $\mathrm{CS}_{\mathrm{cd}}$ & $\mathrm{CS}_{\mathrm{Cd}}$ & $\mathrm{CS}_{\mathrm{CD}}$ & $\mathrm{CS}_{\mathrm{CD}}$ & & $\mathrm{CS}_{\mathrm{cd}}$ & $\mathrm{CS}_{\mathrm{Cd}}$ & $\mathrm{CS}_{\mathrm{CD}}$ & $\mathrm{CS}_{\mathrm{CD}}$ \\
\hline 25 & 2.45 & 1.48 & 2.45 & 0.91 & 1.19 & & 1.30 & 1.37 & 1.56 & 39.94 & 36.21 & 33.58 & 27.94 \\
\hline 50 & 2.45 & 1.48 & 2.45 & 0.97 & 1.09 & 1.0 & 1.37 & 1.4 & 1.73 & 40.21 & 36. & 33.89 & 28.22 \\
\hline 100 & 2.45 & 1.30 & 2.45 & 0.87 & 1.34 & 1.30 & 1.44 & 1.52 & 2.07 & 41.09 & 37.35 & 34.53 & 28.81 \\
\hline 150 & 2.45 & 1.30 & 2.45 & 0.70 & 1.62 & 1.58 & 1.57 & 1.61 & 2.41 & 42.06 & 38.21 & 35.32 & 29.44 \\
\hline 194 & 2.45 & 1.30 & 2.45 & 0.50 & 1.86 & 1.82 & 1.68 & 1.70 & 2.71 & 42.91 & 39.02 & 36.10 & 30.03 \\
\hline
\end{tabular}

250 houses per house type have been analyzed (a similar approach has been used in [30]). Case study $\mathbf{C S}_{\mathbf{c d}}$ is the business-as-usual base case (with no DER systems or connection EV-metro), and corresponds to the model depicted in Fig. 2, removing the connecting line 1 and the blocks grouped in 2. $\mathbf{C S}_{\mathbf{C d}}$ implements the connection between the EVs and the metro electrical substation (see Fig. 2, removing the blocks grouped in 2). In case study $\mathbf{C S}_{\mathbf{c D}}$ DER has been implemented but with separate metro and EV optimization (removing their electrical connection), and CS $_{\text {CD }}$ corresponds to the complete model implementing DER systems and the joint optimization of EVs and the metro substation (see Fig. 2).

\section{RESULTS AND DISCUSSION}

\section{A. Results of the Case Studies}

Table III shows the net cost of the final consumed energy (calculated with (2), (4) and (12) and so subtracting selling incomes) and DER investment and maintenance costs, (6) - (11), Table IV shows the contracted power costs, (3) and (13), other system costs (contracted thermal power, (4), and EV extra battery costs, (14)) and the final total cost (1) summing up all the costs. For $\mathbf{C S}_{\mathbf{c d}}$, it can be seen how the district and the total costs increase with the number of EVs, due to the extra load of more EVs. For the metro substation, as the systems have not been interconnected, the costs have not been affected.

For $\mathbf{C S}_{\mathbf{C d}}$, in comparison with $\mathbf{C S}_{\mathbf{c d}}$, the power and energy costs for the metro system are considerably lower (around $44 \%$ for both power and energy costs), and decrease with the number of EVs. This has been caused by the extra storage capacity provided by more EVs, and the metro taking advantage of it, storing more regenerative braking energy.

In $\mathbf{C S}_{\mathbf{c D}}$, metro costs go back to those of the base case. However, district energy costs decrease significantly (more than $60 \%$, in comparison with $\mathbf{C S}_{\mathbf{C d}}$ ) due to the added distributed generation (consuming less energy from the grid),

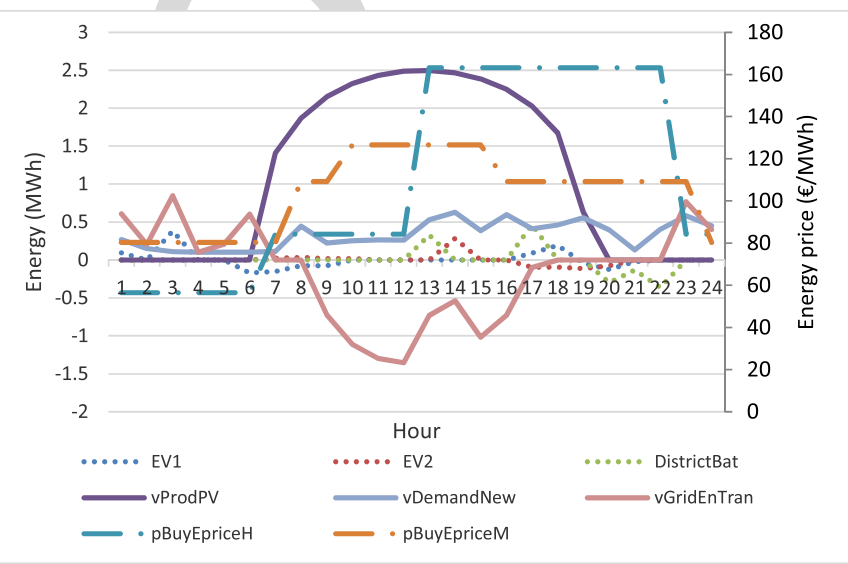

Fig. 6. Operation of DER and EV storage in a summer day.

and the load shifting capacity. The costs of DER investments are compensated with the resulting operation, so the total costs are slightly smaller (around 7\%) than those in $\mathbf{C S}_{\mathbf{C d}}$.

Finally, in $\mathbf{C S}_{\mathbf{C D}}$ DER investment and maintenance costs increase significantly (being nearly half of the total costs), but almost all other costs are lower than in previous cases, especially for the thermal and electric energy costs for both metro and district systems. This reduction is due to the higher energy flow from the renewable generation to both the district (including the EV load) and metro loads. As it can be seen in Fig. 6, when the energy price is low or when the solar production is high, the energy is used to charge EVs and stationary batteries (positive values of EV1, EV2 and DistrictBat), and PV production surplus is sold back to the grid (negative values). When the solar energy decreases, EVs and batteries discharge (negative values of EV1, EV2 and DistrictBat) supplying energy to metro and district loads.

\section{B. Comparison With the Base Case}

The total costs of $\mathbf{C S}_{\mathbf{C d}}, \mathbf{C S}_{\mathbf{c D}}$ and $\mathbf{C S}_{\mathbf{C D}}$ have been compared with those of the base case $\mathbf{C S}_{\mathbf{c d}}$ (see Table V, 
TABLE V

Costs InCREMEnt With Respect to the Base CASE

\begin{tabular}{cccc}
\hline \hline & $\mathrm{CS}_{\mathrm{Cd}}$ & $\mathrm{CS}_{\mathrm{CD}}$ & $\mathrm{CS}_{\mathrm{CD}}$ \\
\hline Elect. metro costs inc. & -37 to $-51 \%$ & $0 \%$ & -76 to $-86 \%$ \\
Elect. district costs inc. & 14 to $23 \%$ & -49 to $-52 \%$ & -34 to $-38 \%$ \\
Ther. district costs inc. & $0 \%$ & -93 to $-94 \%$ & -94 to $-95 \%$ \\
Total average costs & $\mathbf{- 9 \%}$ & $\mathbf{- 1 6 \%}$ & $\mathbf{- 3 0 \%}$ \\
\hline
\end{tabular}

TABLE VI

Sensitivity Analysis For Metro Energy Profiles (Total Costs With 194 EVs)

\begin{tabular}{cccc}
\hline \hline Parameter change & $\mathrm{CS}_{\mathrm{dd}}(\mathrm{M} €)$ & $\mathrm{CS}_{\mathrm{CD}}(\mathrm{M} €)$ & Change (\%) \\
\hline Original & 42.90 & 30.03 & $-30.0 \%$ \\
Metro profile $-20 \%$ & 39.93 & 28.19 & $-29.4 \%$ \\
Metro profile $+20 \%$ & 45.88 & 31.89 & $-30.5 \%$ \\
District energy price $-20 \%$ & 37.56 & 27.12 & $-27.8 \%$ \\
District energy price $+20 \%$ & 48.24 & 32.01 & $-33.7 \%$ \\
Metro energy price $-20 \%$ & 39.93 & 29.37 & $-26.4 \%$ \\
Metro energy price $+20 \%$ & 45.88 & 30.18 & $-34.2 \%$ \\
\hline
\end{tabular}

the \% range is due to the number of EVs) to analyze the importance of the interaction between the EV storage and the metro system and DER systems. It can be seen that connecting the metro with the district, case $\mathbf{C S}_{\mathbf{C d}}$, leads to an important cost reduction for the metro system, but to an increment for the district electricity costs. Conversely, $\mathbf{C S}_{\mathbf{c D}}$ shows that DER systems do not change the metro related costs, but reduce significantly the district costs, and with the introduction of the HP system the thermal energy costs (from natural gas) almost disappear. Finally, $\mathbf{C S}_{\mathbf{C D}}$ shows that connecting the metro with the district and implementing DER systems also increases the metro substation benefits while district electricity costs are around $36 \%$.

Looking at the system as a whole, the total costs (Table IV) give a clear overview of the maximum expected benefits of implementing the intermediate or the complete cases. For instance, just the storage capabilities provided by the EV in $\mathbf{C S}_{\mathbf{C d}}$, already give a considerable benefit (9\%) to the overall system, especially to the metro substation. The inclusion of DER systems in $\mathbf{C S}_{\mathbf{C D}}$ presents a slightly bigger cost reduction $(16 \%)$. Nevertheless, by including both elements $(\mathbf{C S} \mathbf{C D})$, an even larger benefit can be achieved (30\%) proving the existing synergies of approaching the problem globally. It is also important to remark that $\mathbf{C S}_{\mathbf{C D}}$ total benefits are larger than the sum of $\mathbf{C S}_{\mathbf{C d}}$ and $\mathbf{C S}_{\mathbf{c D}}$ benefits, showing the importance of the joint optimization. Finally, the EV penetration level does not affect significantly the expected benefits, i.e. the cost of the EV load is relatively small in comparison to other loads, and the inclusion of EVs reduces the battery costs as well.

\section{Sensitivity Analysis}

A sensitivity analysis on some of the main model parameters has been carried out, to provide insight on the potential applicability of the results in other contexts. The analysis consists in increasing or decreasing by $20 \%$ the metro energy profiles (shown in Fig. 4) and the district and metro energy prices (shown in Table I and Table II). Table VI shows the total costs of the base case $\mathbf{C S}_{\mathbf{c d}}$ and the $\mathbf{C S}_{\mathbf{C D}}$ case for the different value changes. It can be seen that the change in benefits is relatively small for all the considered parameters, with benefits ranging from $26.4 \%$ to $34.2 \%$ (approx. $\pm 4 \%$ variation relative to the original benefits) in the studied sensitivity range. These results suggest that other systems in a similar setup are likely to present comparable synergies as the ones reported in this paper.

\section{CONCLUding REMARKS}

Energy systems within cities are numerous and complex, and potential synergies among them are not always evident. The work developed in this paper provides an example of such synergies by modeling the interconnection and coordinated operation of electricity powered transport systems (EVs and metro), residential loads and distributed energy systems.

The outcomes of the presented study suggest that the energy recovered by the metro regenerative braking can create great cost reductions for the metro system, with the assistance of EVs used as energy storage. When distributed energy sources are included, this benefit is even larger, not only for the metro system, but also for the EV owners and prosumers. Moreover, it can be seen from the results that a higher penetration of EVs represents higher bulk storage capacity, translating to a greater profit for the metro system without a significant increment of prosumers energy costs (due to more EV loads). Also, the overall global benefit (including metro, EV and district costs) is approximately $30 \%$ for any number of EVs, in comparison with the independent systems with no DER systems installed. It is important to note that this value almost does not depend on the number of EVs considered, and that the individual benefits of the systems are not equally shared, and thus, adequate business models should be developed.

It is important to remark that the results obtained in these analyses are particular to this setup and to the assumptions considered (e.g. energy tariffs, EV availability, metro profiles). Therefore, different systems (for instance, other energy prices and/or DER costs) are likely to present different values for these benefits. Nevertheless, the overall conclusions are likely to hold, showing the existence of synergies, both physical (due to different energy profiles) and opportunistic (due to different energy tariffs), between energy systems in the smart city.

This paper shows a particular example of synergies between systems, but there are many more technologies and schemes that can be studied in order to find more interactions between urban energy systems, such as public buses or car sharing. The analysis developed, despite being optimistic due to a perfect coordination among systems, shows the importance of such synergies to reduce global costs, and can be seen as a starting point for more related research and further analysis.

\section{ACKNOWLEDGMENT}

The authors would like to express their gratitude to all partner institutions within the Erasmus Mundus Joint Doctorate Program in Sustainable Energy Technologies and Strategies (SETS) as well as to the European Commission for their support. 


\section{REFERENCES}

[1] J. Villar, I. Trigo, C. A. Díaz, and P. Gonzalez, "Cost-benefit analysis of plug-in electric vehicles penetration," in Proc. 10th Int. Conf. Eur. Energy Market (EEM), May 2013, pp. 1-8.

[2] A. González-Gil, R. Palacin, P. Batty, and J. P. Powell, "A systems approach to reduce urban rail energy consumption," Energy Convers. Manage., vol. 80, pp. 509-524, Apr. 2014.

[3] A. González-Gil, R. Palacin, and P. Batty, "Sustainable urban rail systems: Strategies and technologies for optimal management of regenerative braking energy," Energy Convers. Manage., vol. 75, pp. 374-388, Nov. 2013.

[4] M. Peña-Alcaraz, A. Fernández, A. P. Cucala, A. Ramos, and R. R. Pecharromán, "Optimal underground timetable design based on power flow for maximizing the use of regenerative-braking energy," Proc. Inst. Mech. Eng. F, J. Rail Rapid Transit, vol. 226, no. 4, pp. 397-408, Jul. 2012.

[5] Y. Warin, R. Lanselle, and M. Thiounn, "Active substation," presented at the 9th World Congr. Railway Res. (WCRR), Lille, France, 2011.

[6] Yuntamiento de Madrid (Madrid City Council). Aprobado el nuevo Protocolo para Episodios de Alta Contaminación por $\mathrm{NO}_{2}$ (New Protocol Approved for High $\mathrm{NO}_{2}$ Pollution Episodes). Accessed: Jun. 8, 2016. [Online]. Available: http://goo.gl/rJzlvO

[7] J. García-Villalobos, I. Zamora, J. I. San Martín, F. J. Asensio, and V. Aperribay, "Plug-in electric vehicles in electric distribution networks: A review of smart charging approaches," Renew. Sustain. Energy Rev., vol. 38, pp. 717-731, Oct. 2014.

[8] I. J. Fernández, C. F. Calvillo, A. Sánchez-Miralles, and J. Boal, "Capacity fade and aging models for electric batteries and optimal charging strategy for electric vehicles," Energy, vol. 60, pp. 35-43, Oct. 2013.

[9] H. Lund and W. Kempton, "Integration of renewable energy into the transport and electricity sectors through V2G," Energy Policy, vol. 36, no. 9, pp. 3578-3587, Sep. 2008.

[10] J. Villar, C. A. Diaz, P. Gonzalez, and F. A. Campos, "Wind and solar integration with plug-in electric vehicles smart charging strategies," in Proc. 11th Int. Conf. Eur. Energy Market (EEM), May 2014, pp. 1-6.

[11] Metro de Madrid (Madrid's Metro). Train2Car Project. Accessed: Apr. 18, 2017. [Online]. Available: https://www. metromadrid.es/en/conocenos/proyectos_en_marcha/I_D_i/Proyecto06/

[12] EPSRC. TransEnergy_Road to Rail Energy Exchange (R2REE). Accessed: May 6, 2017. [Online]. Available: http://gow.epsrc. ac.uk/NGBOViewGrant.aspx?GrantRef=EP/N022289/1

[13] D. Connolly, H. Lund, B. V. Mathiesen, and M. Leahy, "A review of computer tools for analysing the integration of renewable energy into various energy systems," Appl. Energy, vol. 87, no. 4, pp. 1059-1082, Apr. 2010.

[14] P. Moreno-Torres, G. Navarro, M. Blanco, and M. Lafoz, "Multifunctional test bench for the emulation and testing of electric vehicle fastcharging from urban railway power lines," in Proc. IEEE Int. Conf. Ind. Technol. (ICIT), Mar. 2015, pp. 1081-1087.

[15] C. F. Calvillo, A. Sánchez-Miralles, and J. Villar, "Assessing low voltage network constraints in distributed energy resources planning," Energy, vol. 84, pp. 783-793, May 2015.

[16] M. Davis. (Jan. 25, 2012). PROJECT SECH-SPAHOUSEC Análisis del Consumo Energético del Sector Residencial en España (Analysis of the Energy Consumption of the Spanish Residential Sector), Build Up. Accessed: Sep. 29, 2016. [Online]. Available: http://www. buildup.eu/en/node/23244

[17] K. Richa, C. W. Babbitt, G. Gaustad, and X. Wang, "A future perspective on lithium-ion battery waste flows from electric vehicles," Resour. Conserv. Recycl., vol. 83, pp. 63-76, Feb. 2014.

[18] PluginCars. Replacing EV Batteries: Your Costs Will Vary. Accessed: May 26, 2015. [Online]. Available: http://goo.gl/j4Fu4u

[19] W. Carvajal-Carreño, A. P. Cucala, and A. Fernández-Cardador, "Optimal design of energy-efficient ATO CBTC driving for metro lines based on NSGA-II with fuzzy parameters," Eng. Appl. Artif. Intell., vol. 36, pp. 164-177, Nov. 2014.

[20] Line 3 of Madrid's Metro. Accessed: May 31, 2016. [Online]. Available: http://www.planometromadrid.org/en-line-3-metro-madrid.php

[21] S. Su, T. Tang, and Y. Wang, "Evaluation of strategies to reducing traction energy consumption of metro systems using an optimal train control simulation model," Energies, vol. 9, no. 2, p. 105, Feb. 2016.

[22] Google Maps. Madrid. Accessed: Sep. 29, 2016. [Online]. Available: https://goo.gl/OXkL24

[23] Metro de Madrid (Madrid's Metro). Line 3 Time Schedule. Accessed: Sep. 29, 2016. [Online]. Available: https://goo.gl/C1h8sD
[24] M. Dominguez, A. Fernandez-Cardador, A. P. Cucala, and R. R. Pecharroman, "Energy savings in metropolitan railway substations through regenerative energy recovery and optimal design of ATO speed profiles," IEEE Trans. Autom. Sci. Eng., vol. 9, no. 3, pp. 496-504, Jul. 2012.

[25] Ayuntamiento de Madrid (Madrid City Council). Aparcamientos Municipales (Municipal Parking Lots). Accessed: Sep. 29, 2016. [Online]. Available: http://goo.gl/ihYlD2

[26] PluginCars. Eight Tips to Extend Battery Life of Your Electric Car. Accessed: Jun. 18, 2016. [Online]. Available: http://goo.gl/ExBCTW

[27] European Commission-Joint ResearchCentre. Photovoltaic Geographical Information System (PVGIS). Accessed: Sep. 28, 2016. [Online]. Available: https://goo.gl/6QagIh

[28] (May 1 2013). How Much do Smart Meters Cost?-WeblogPost by Chris King. Accessed: Sep. 29, 2016. [Online]. Available: https://blogs.siemens.com/smartgridwatch/stories/957/

[29] REE. Proyecto INDEL-Atlas de la Demanda eléctrica española (INDEL Proyect-Atlas of the Spanish Electric Demand). Accessed: Sep. 29, 2016. [Online]. Available: https://goo.gl/6g4Xjg

[30] C. F. Calvillo, Á. Sánchez-Miralles, and J. Villar, "Price-maker optima planning and operation of distributed energy resources," in Proc. 13th Int. Conf. Eur. Energy Market (EEM), 2016, pp. 1-5.

[31] Iberdrola. Residential Time-of-use Electric Tariff. Accessed: Sep. 29, 2016. [Online]. Available: https://www.iberdrola.es/home/ electricity

[32] Iberdrola. Residential Gas Tariff. Apr. 18, 2017. [Online]. Available: https://www.iberdrola.es/home/gas/home-gas-plan

[33] Endesa. High Voltage Commercial Time-of-Use Electric Tariff. Accessed: Sep. 29, 2016. [Online]. Available: https://www. endesaclientes.com/companies/optimum-rate.html

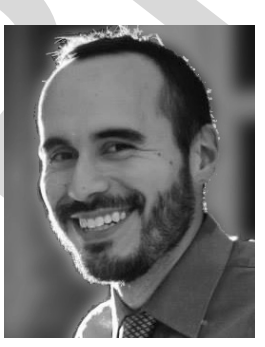

Christian F. Calvillo (M'15) received the B.S. degree in mechatronics and the M.S. degree in electronic systems from the Tecnológico de Monterrey, Monterrey, México, in 2008 and 2012, respectively.

$\mathrm{He}$ is currently pursuing the Erasmus Mundus Joint Doctorate in sustainable energy technologies and strategies with the Comillas Pontifical University, Spain, the KTH Royal Institute of Technology, Sweden, and the Delft University of Technology, The Netherlands. His research interest includes smart city optimization models, renewable energy systems, electric vehicles, and distributed generation and storage.

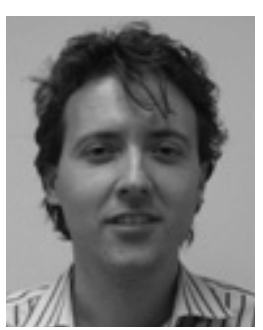

Álvaro Sánchez-Miralles received the degree in electronic engineering from the ICAI Engineering School, Comillas Pontifical University, Madrid, Spain, in 1998, and the Ph.D. degree in ingeniero industrial from Comillas Pontifical University in 2003. He has a more experience in industry joint research projects applying artificial intelligence to electric energy systems in collaboration with Spanish companies. He has been a Principal Researcher of over ten of these projects. His interest areas are smart grids, electrical vehicles, and security systems.

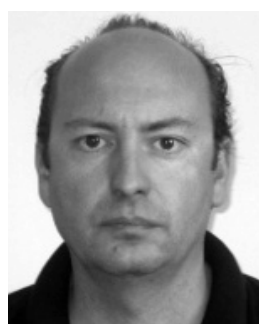

José Villar received the degree in electronic engineering and the Ph.D. degree from the School of Industrial Engineering ICAI, Comillas Pontifical University, Madrid, Spain, in 1991 and 1997, respectively. Since 1997, he has been a Researcher with the Institute for Research in Technology, ICAI, and has been the Deputy Director since 2004. He is a Teacher of electronics with the ICAI Electronic Department. He has participated in more than 40 research projects with industry and administrations. His areas of interest include operation and planning of power systems and electrical vehicles or integration of renewable generation. 